\title{
O uso do Software Livre na redução da exclusão digital
}

\author{
Liane Baqueiro dos Santos
}

\author{
Departamento de Ciência da Computação, Universidade Federal da Bahia, \\ Av. Adhemar de Barros, s/n, Instituto de Matemática, \\ Campus de Ondina, Salvador, BA, Brasil \\ liane@im.ufba.br
}

\begin{abstract}
Resumo - Esse artigo se propõe a apresentar a realidade brasileira em termos de exclusão digital, mostrar as vantagens do Software Livre (SL) na ótica da inclusão digital, informar iniciativas brasileiras de uso do SL na alfabetização digital e apresentar uma proposta de combate à exclusão digital na Bahia.
\end{abstract}

Palavras Chave: Software Livre, Exclusão Digital, Computadores e Sociedade.

\section{Exclusão digital: a reali- dade brasileira}

Diante da ânsia por obter acesso às mais novas tecnologias da informação e da comunicação, os países mais ricos e desenvolvidos têm ditado a Sociedade da Informação como regra para o mundo. O conhecimento digital deixou de ser optativo e passou a ser decisivo e necessário. As opções de emprego, por exemplo, privilegiam candidatos com esse conhecimento. Percebe-se, portanto, que a exclusão digital é uma forma legítima de exclusão social.

No Brasil, a sociedade tenta alcançar os rumos do mundo, mas os números nos mostram que essa tentativa está deixando a desejar. Segundo dados de pesquisa realizada pela Fundação Getúlio Vargas (FGV)[4], em parceria com o Comitê para Democratização da Informática (CDI)[1], Sun Microsystems e Usaid, divulgado em abril desse ano, os números de exclusão digital do Brasil são alarmantes. Apenas $12,5 \%$ da população tem acesso a computador e $8,3 \%$ tem acesso a Internet.

O que é mais preocupante é que esses dados representam a porcentagem de pessoas que têm acesso a tais tecnologias, mas ter acesso não significa uso correto e aproveitamento inteligente das informações de acordo com as necessidades. Ou seja, a real e importante inclusão digital pode não estar sendo vivida nem pelos $12,5 \%$ da população.

A verdadeira inclusão digital proporciona benefícios multidirecionais, haja vista que ela socializa e dinamiza o acesso à informação, além de desenvolver a criatividade e o intelecto. No âmbito do comércio e negócios, por exemplo, traz mais agilidade nas transações e qualidade nos resultados; em termos sociais, facilita o exercício da cidadania por dar ao indivíduo mais consciência de seus direitos e deveres; na área educacional, porporciona ferramentas de apoio didático, além de oferecer uma grande fonte de informações e conhecimento. Esses são apenas alguns exemplos de áreas agraciadas com a inclusão digital. Seria impossível, aqui, dimensionar tamanho benefício.

Podemos considerar, portanto, que existem dois tipos de exclusão digital. A exclusão absoluta é vivida pelos chamados analfabetos digitais, indivíduos que não possuem acesso nem qualquer conhecimento sobre computadores, ou seja, nunca se sentaram em frente a um PC. Não é raro encontrar aquele que chega a ter "medo" de manusear a máquina e, diante da resistência, acabam por transformar o computador num "bicho de sete cabeças".

Já a exclusão relativa é vivenciada por aqueles que têm acesso ao computador e, no entanto, em relação a um referencial, são con- 
siderados excluídos, seja por terem pouco conhecimento sobre o uso correto dos computadores, seja por serem defasados tecnologicamente. Exemplificando com uma comparação: de um lado, tem-se uma grande empresa que dispõe de recursos para adquirir tecnologias de ponta, estando sempre atualizada tecnologicamente e oferecendo continuamente cursos de reciclagem a seus funcionários. Do outro lado, tem-se uma microempresa ou um trabalhador autônomo da mesma área, com tecnologias já ultrapassadas e recursos escassos. O segundo lado pode ser considerado excluído digital em relação ao primeiro, pois encontra-se defasado em tecnologia, o que, conseqüentemente, resultará numa exclusão social e econômica. Isso porque a grande empresa com certeza será a preferida pelos clientes, por poder oferecer teoricamente os melhores serviços.

Ainda com base nos dados dos estudos da FGV, foi sugerido que alunos que possuem computador em casa com acesso à Internet têm um melhor rendimento escolar (foram percebidas melhoras de $17 \%$ em matemática e $13 \%$ em português), comprovando que investir na inclusão digital traz reflexos positivos no processo educacional.

Outro dado importante nos resultados é que a média de idade dos excluídos é menor ( 28 anos) do que a dos incluídos (31 anos). Ou seja, os jovens, que são futuro do nosso país, estão imersos na exclusão digital.

Esses dois últimos dados deixam mais clara ainda a urgência em reverter essa situação, pois do contrário não poderemos ter grandes esperanças de que o Brasil tome um rumo melhor.

Vivemos num mundo cada vez mais competitivo e onde é imposta à sociedade uma nova dinâmica, baseada no acesso incondicional à informação. Por isso é preciso que Governo e sociedade civil se unam para mudar esse quadro de exclusão, pois do contrário, afundaremos ainda mais no atraso tecnológico e conseqüentemente, isolamento econômico e social.

Diante da realidade econômica brasileira, é de extrema importância pensar soluções menos dispendiosas para o combate à exclusão digital. Uma boa solução seria a adoção de Software Livre (SL) pelos programas que têm o objetivo de minimizar a exclusão.

\section{Vantagens do Software Livre favoráveis à inclusão digital}

Com a evolução da informática, houve uma mudança de ótica, passando de uma programação orientada a hardware para uma programação baseada na lógica, onde o software ganha grande importância. Portanto, a produção de softwares acessíveis a todos representa econômica e tecnologicamente um grande passo facilitador da inclusão digital. O software livre apresenta boas soluções para os dois tipos de exclusão citados na seção anterior.

Como saída viável para os analfabetos digitais, o SL permite a disseminação da tecnologia e da informação para qualquer pessoa que queira ter acesso diferentemente do software proprietário, onde apenas aqueles que podem (leia-se possuem recursos financeiros) têm acesso a tecnologia. Isso porque, embora não seja uma condição necessária para o software ser considerado livre, estes, na grande maioria das vezes, não são comercializados. Eles estão disponíveis para download na rede ou então é cobrado apenas o custo de reprodução. O preço de software proprietário é bem superior ao do hardware, e chega a ultrapassar a casa dos milhares em alguns casos. Imagine se, além dos gastos com hardware, ainda for necessário pagar os altos preços das licenças dos softwares não livres.

Pelos dados da FGV, a renda média entre os incluídos é de $\mathrm{R} \$ 1.677,00$, enquanto a dos excluídos é de $\mathrm{R} \$ 452,00$. Esse valor é muito baixo e não cobre sequer os custos com hardware. O mais importante é que a opção por SL pode até ser motivada pelo baixo custo, porém isso não acarreta em perda na qualidade do produto adquirido. Alguns softwares consagrados comprovam essa afirmativa, como o servidor de páginas Apache[5], a suíte OpenOffice.org[8], e o navegador Mozilla[6], entre outros, que são de extrema qualidade, são desenvolvidos colaborativamente e não deixam nada a desejar em relação aos similares proprietários.

Os indivíduos relativamente excluídos também podem usufruir dos benefícios que surgem com o uso do SL. Como a condição necessária para um software ser considerado livre é ter seu código aberto, qualquer atu- 
alização ou modificação fica disponível a todos, evitando assim gastar dinheiro a cada nova versão que surja do software utilizado e impedindo que aqueles que não possuem recursos para aquisição das novas versões fiquem atrasados em termos de tecnologia (exclusão social). E ainda, o uso do software livre permite um maior aperfeiçoamento digital. Como são tecnologias acessíveis a quem assim o desejar, uma pessoa que antes lidava com um só tipo de tecnologia em seu trabalho, por não possuir recursos financeiros para aquisição de novas tecnologias, pode agora fazer uso de tecnologias que satisfaçam as suas necessidades, diversificando seus conhecimentos e até mesmo combinando tecnologias para produzir soluções mais completas.

Por ser código aberto, o indivíduo que antes era apenas um usuário, um consumidor da tecnologia, pode agora entender o seu funcionamento e ser capaz de produzir novas tecnologias ou até mesmo aperfeiçoar as já existentes. Portanto, o SL também estimula e possibilita o desenvolvimento e crescimento da área tecnológica.

Os custos para se ter acesso adequado à tecnologia não se resumem aos gastos imediatos com hardware e software. Existem também gastos com manuntenção das tecnologias. É muito comum encontrar laboratórios de computação, em escolas públicas por exemplo, com bons equipamentos mas que encontram-se desativados, na maioria das vezes por falta de recursos para manter o laboratório. O SL também é vantajoso nesse aspecto. Ele possui uma manutenção mais fácil e mais rápida, por possuir código aberto. Além disso, os sistemas operacionais livres são menos suscetíveis ao ataque de vírus, por isso é muito mais seguro e confiável montar uma rede usando SL.

Fazendo uma visão panorâmica do conhecimento e produção digital no mundo, percebese que existe uma grande desigualdade, que acaba refletindo em outras áreas, principalmente econômicas e sociais. Especialmente ao comparar países desenvolvidos com países em desenvolvimento ou subdesenvolvidos, é notório que os primeiros, detentores das tecnologias mais populares e lucrativas possuem um índice de inclusão digital muito maior do que os países do segundo grupo.

O software livre carrega uma grande vantagem que é o fato de deixar todos os seus usuários em pé de igualdade em conhecimento tecnológico. Imagine se todo o mundo passasse a usar apenas SLs. Os softwares que fossem desenvolvidos estariam disponíveis a qualquer pessoa, tornando o conhecimento simultâneo e democrático e facilitando a troca de informações. Com isso, com certeza essa desigualdade digital existente atualmente seria amenizada.

\section{Iniciativas brasileiras de minimização da exclusão com uso de SL}

Embora o SL represente aquisição democrática da tecnologia, é preciso que o acesso a elas torne-se real para que os índices de exclusão diminuam. Ou seja, é necessário que esse processo esteja associado a iniciativas educativas, para que as pessoas aprendam a usar o computador e acessar a Internet e possam tirar o melhor proveito dessas tecnologias.

Algumas iniciativas já foram tomadas no Brasil, e aqui destacarei três delas: o projeto Rede Escolar Livre, do Rio Grande do Sul [2]; o Projeto de Informática Educativa da Prefeitura da cidade do Rio de Janeiro [3] e os Telecentros, na cidade de São Paulo[9].

O projeto Rede Escolar Livre é resultado da parceria entre o governo do estado do Rio Grande do Sul, através da Secretaria Estadual da Educação e da Companhia de Processamento de Dados do Estado (PROCERGS). Lançado em maio de 2001, tem como objetivo principal viabilizar o uso da Informática nas escolas públicas do estado do Rio Grande do Sul, possibilitando assim a inclusão de alunos, professores, funcionários e da comunidade escolar nos avanços tecnológicos do mundo atual. O programa beneficia escolas com mais de 100 alunos, equipando-as com microcomputadores ligados em rede local, utilizando softwares livres e com acesso a Internet. As escolas que estão ligadas ao projeto contam com alguns softwares livres em seus laboratórios, entre eles o GNU/Linux. Como o software livre trabalha com código aberto, permite que os programadores tenham acesso e possam modificar as suas configurações a partir de suas necessidades. Além disso, possibilita que um mesmo programa possa ser ins- 
talado em quantas máquinas o usuário desejar. A economia de custo do software livre é outra vantagem. Com a sua utilização no Rede Escolar Livre RS serão economizados cerca de $\mathrm{R} \$ 40$ milhões.

O Projeto Informática Educativa da Prefeitura da Cidade do Rio de Janeiro também foi lançado em 2001 como um grande projeto para as Unidades Escolares. Busca a utilização de novas tecnologias, especialmente aquelas ligadas à Informática. As ações reforçam a idéia de revitalização da Escola Municipal como efetivo espaço de socialização e aprendizagem. Uma das metas do programa de Informática Educativa é dotar as Escolas de Laboratórios de Informática e criar um espaço onde o professor possa fazer uso das tecnologias para auxiliar no processo pedagógico, agregando mais valor à Escola. O público alvo são os alunos da Rede, e os recursos empregados ajudarão no processo de inclusão dos alunos ao mundo digital, a partir de um contato inicial com o computador até a fase de utilização como ferramenta de auxílio nas atividades.

A principal ação do projeto de Inclusão Digital da Prefeitura de São Paulo é a construção dos Telecentros. São 59 Telecentros instalados atualmente na cidade de São Paulo, atendendo mais de 90 mil pessoas e a meta é ter até o final de 2003107 unidades instaladas e em funcionamento na cidade. Os computadores dos Telecentros são equipados com o sistema operacional GNU/Linux. A adoção de SL foi de extrema importância para reduzir os custos dos equipamentos. O custo de instalação de um novo Telecentro, varia de $\mathrm{R} \$ 130$ mil a R\$ 275 mil. Caso os programas usados nos equipamentos das unidades não fossem softwares livres, este custo aumentaria em pelo menos $50 \%$, pois a escolha de softwares livres permite a aquisição de computadores com hardware de menor capacidade, menos potentes, portanto mais baratos, tendo um aproveitamento igual a hardwares superiores, mais caros, utilizando Windows. Do total de computadores em cada Telecentro, $75 \%$ são usados para os cursos oferecidos e os $25 \%$ restantes são de uso livre, que tem uma frequência de mais de 5 mil pessoas por semana. Desde o início do projeto em junho de 2001, mais de 17 mil pessoas já se formaram nos cursos oferecidos nos Telecentros, que são o de Informática Básica e as Oficinas especiais. O Curso de Informática Básica tem o objetivo de capacitar as pessoas com pouco ou nenhum conhecimento em informática a utilizar os equipamentos de forma livre. As oficinas especiais foram criadas para orientar o uso cidadão dos equipamentos e capacitar profissionalmente. Três oficinas estão pleno funcionamento: agência de notícias comunitária, criação de websites (HTML) e tratamento de imagens com Gimp [7].

\section{Uma proposta para a Bahia}

É importante observar que a presença do Governo nos programas de exclusão digital lhes dá uma importância e projeção maiores. Projetos isolados são válidos mas não possuem um alcance significativo que resulte em modificações notórias nos índices de exclusão.

Infelizmente aqui na Bahia não existe, por parte do Governo, uma iniciativa real e de impacto com o intuito de minimizar a exclusão digital no Estado. No país em geral, os índices são alarmantes. Na Bahia a situação não é diferente. Os resultados do estudo da FGV mostraram que apenas $4,61 \%$ da população baiana tem acesso a computador, estando o estado em quarto lugar em termos de inclusão digital no Nordeste (empatado com o Ceará).

Uma boa solução para tentar reverter esse quadro seria um projeto, parceria entre Governo do Estado e instituições de ensino da área de computação e educação (públicas e/ou privadas). Esse projeto incentivaria a criação de centros comunitários de aprendizagem nas periferias da capital e nas cidades do interior, além de laboratórios em todas as escolas públicas.

Ao Governo caberia a responsabilidade de oferecer a infra-estrutura necessária para criação desses centros e laboratórios (espaço físico, bancadas, cadeiras, cabos, etc) e capitalizar recursos para custear as máquinas. Às instituições de ensino caberia disponibilizar voluntários para ensinar nesses centros e laboratórios, além de organizar o cronograma dos cursos.

Por todas as vantagens apresentadas, obviamente esse projeto seria realizado com uso de software livre. Uma opção viável por ser bastante econômica é instalar servidor de terminais GNU/Linux. Essa tecnologia permite uti- 
lizar máquinas com recursos de hardware ultrapassados, e até mesmo terminais burros, bastando apenas um investimento maior em uma máquina, que será o servidor, e numa boa infraestrutura de rede a fim de obter um desempenho de qualidade.

Para garantir a demanda de professores voluntários para os centros e laboratórios, uma boa solução seria criar uma matéria em cada curso da área de computação com a ementa de serem, os estudantes, instrutores centros durante um semestre, e no fim da disciplina, apresentassem um relatório dos resultados.

Como a realidade em termos de inclusão clama por medidas urgentes, o cronograma do curso seria intensivo, a fim de que mais pessoas sejam assistidas num curto espaço de tempo. Ele seria definido de forma que fosse possível ao aluno aprender a usar o computador como fonte de informação e instrumento facilitador para atender suas necessidades. Com a vantagem dos softwares utilizados terem código aberto, poderia ser criado um curso de especialização para aqueles alunos que se destacassem e tivessem interesse em conhecer o que está por trás do software. Eles receberiam diretivas para estudar e pesquisar e, quem sabe, tornarem-se desenvolvedores de software. Dessa forma, estariam sendo incentivadas produções de software livre, e o mais importante, despertando o interesse desses alunos pela área de tecnologia, e talvez até estimulando-os a se dedicar rumo a essa formação acadêmica.

Além do espaço reservado ao curso, estariam disponíveis máquinas de acesso gratuito para todos, mesmo depois de concluído o curso, para que possam pôr em prática seus aprendizados e que usufruam dele da melhor forma possível. Cada aluno ao final do curso receberia um certificado de conclusão, a fim de ficar documentada sua participação e provar que possui conhecimento digital.

A definição dos campos de atuação e da ordem em que estes serão beneficiados com a implantação dos centros comunitários seria feita da seguinte forma: Os trabalhos se iniciariam nas grandes cidades baianas (Salvador, Feira de Santana e adjacências). Dentro dessas cidades, seria necessário um levantamento dos índices percentuais de exclusão priorizando aqueles locais com os maiores índices, a fim de diminuir a desigualdade digital. Depois o mesmo processo se- ria realizado nas cidades de porte médio, e depois nas pequenas cidades, equiparando assim todas as cidades baianas em termos de conhecimento digital.

\section{Conclusão}

Percebemos que a realidade brasileira em termos de exclusão digital apresenta um quadro bastante preocupante que se reflete negativamente, pricipalmente nas áreas econômica, social e educacional. Além disso, este atraso tecnológico nos deixa ainda mais distantes dos países desenvolvidos.

É preciso, portanto, que a exclusão digital seja uma preocupação fundamental da sociedade civil e que projetos com intuito de extingui-la sejam levados à esfera pública para que ganhem uma maior projeção e alcancem resultados positivos e notórios.

\section{Referências}

[1] Comitê de democratização de informação. URL: http://www.cdi.org.br. Último acesso em 29 de setembro de 2003.

[2] Projeto rede escolar livre. URL: http: //www.redeescolarlivre.rs.gov.br. Último acesso em 29 de setembro de 2003.

[3] Secretaria de educação do rio de janeiro. URL: http://www.rio.rj.gov.br/sme/. Último acesso em 29 de setembro de 2003.

[4] Sítio das pesquisas da fgv. URL: http:// www2.fgv.br/ibre/cps/mapa_exclusao/ apresentacao/apresentacao.htm\%. Último acesso em 29 de setembro de 2003.

[5] Sítio oficial da fundação apache. URL: http: //www . apache.org. Último acesso em 29 de setembro de 2003.

[6] Sítio oficial da fundação mozilla. URL: http://www.mozilla.org. Último acesso em 29 de setembro de 2003.

[7] Sítio oficial da projeto gimp. URL: http: //www.gimp.org. Último acesso em 29 de setembro de 2003. 
[8] Sítio oficial do projeto openoffice.org. URL: http://www.openoffice.org. Último acesso em 29 de setembro de 2003.

[9] Telecentros de são paulo. URL: www. telecentros.sp.gov.br. Último acesso em 29 de setembro de 2003. 